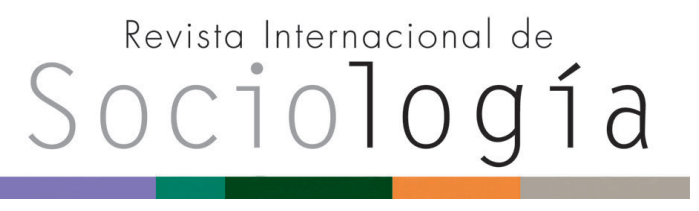

Revista Internacional de Sociología RIS vol. 78 (3), e161, julio-septiembre, 2020, ISSN-L:0034-9712 https://doi.org/10.3989/ris.2020.78.3.19.005

\section{ORIGEN SOCIAL Y PARO: ¿IMPORTA LA OCUPACIÓN DE LOS PADRES PARA EVITAR EL DESEMPLEO?}

\author{
JUAN IGNACIO MARTÍNEZ PASTOR \\ UNED \\ jimartinez@poli.uned.es \\ ORCID iD: https://orcid.org/0000-0002-8485-5510
}

Cómo citar este artículo / Citation: Martínez Pastor, J. I. 2020. "Origen social y paro: ¿importa la ocupación de los padres para evitar el desempleo?". Revista Internacional de Sociología 78(3):e161. https://doi. org/10.3989/ris.2020.78.3.19.005

\section{RESUMEN}

Este artículo plantea tres objetivos. El primero, saber si el origen social influye en la probabilidad de estar parado y, en segundo lugar, en caso de que se sea así, averiguar si esa influencia se mantiene incluso comparando a individuos con el mismo nivel educativo. El tercer objetivo es determinar si el efecto del origen social en el paro varía en cada nivel de estudios. Para ello se han manejado 49 encuestas del CIS llevadas a cabo entre 2013 y 2017, y se ha aplicado un modelo de probabilidad lineal. Los resultados muestran que hay un efecto claro del origen social sobre el paro y que este efecto se produce sobre todo indirectamente, a través del nivel educativo. No obstante, el origen social sigue teniendo un efecto incluso controlando por la educación entre los licenciados o graduados universitarios (no ingenieros) y los que tienen la secundaria inicial o menos.

\section{Palabras Clave}

Clases sociales; Educación; Meritocracia; Ventaja compensatoria.

\section{SOCIAL ORIGIN AND \\ UNEMPLOYMENT: DOES PARENTAL OCCUPATION MATTER TO AVOID IT?}

Copyright: () 2020 CSIC. Este es un artículo de acceso abierto distribuido bajo los términos de la licencia de uso y distribución Creative Commons Reconocimiento 4.0 Internacional (CC BY 4.0).

Recibido: 08/01/2019. Aceptado: 20/12/2019. Publicado online: 28/09/2020

\section{Abstract}

The aim of the paper is to know whether the social origin influences the probability of being unemployed and, secondly, if so, to find out whether that influence remains even controlling for educational attainment. The third objective is to determine whether the influence of social origin var-ies depending on the level of education. 49 surveys from the Spanish Centre for Sociological Research carried out between 2013 and 2017 have been handled, and a linear probability model has been applied. The results show that there is a clear effect of social origin on unemployment, and that this effect occurs mainly indirectly, through the educational level. However, social origin continues to have an effect even controlling for education among university graduates (non engineerings) and among those with lower secondary or less education.

\section{KEYWORDS}

Compensatory advantage; Education; Meritocracy; Social classes. 


\section{INTRODUCCIÓN}

Análisis recientes con datos de varios países han demostrado que, en algunos aspectos del mercado laboral, la brecha existente entre los hijos de la clase obrera y los hijos de profesionales es mayor que la brecha de género o que la que se da entre nativos e inmigrantes (Bernardi y Ballarino 2016a). Los análisis que consideran el origen social se han centrado en su influencia sobre los ingresos y el tipo de ocupación que se tiene; sin embargo, se sabe muy poco del efecto del origen social sobre el paro. La situación es paradójica, ya que mientras que la brecha de género o la inmigración en el mercado laboral han sido muy analizadas (valgan estos ejemplos de la última década: Albanesi y Sahin 2018; Muñoz-Comet 2016; Cebolla-Boado, Miyar-Busto y Muñoz-Comet 2015; Jacob y Kleinert 2014; Fernández 2013; MooiReci y Mills 2012; Dustmann, Glitz y Vogel 2010), el efecto del origen social sobre el paro pasa muy desapercibido en los análisis de la estratificación social.

Son varias las causas que explican esta desatención. La primera, que algunas características como el género o el origen étnico se han erigido en las últimas décadas como rasgos identitarios más visibles y socialmente más relevantes que la clase social, y más todavía que la clase social de origen. Esto ha provocado que el género o la inmigración ganen peso como variables independientes en los análisis sociológicos. Sirva como muestra el Libro de Actas del último Congreso Español de Sociología celebrado en Valencia en julio de 2019, que recoge los títulos de todas las ponencias y comunicaciones presentadas. En dicho libro, la palabra "género" aparece 119 veces; "inmigración" o "inmigrante (s)", 51 veces; "clase (s) social (es)", 9 veces; "origen social", una sola vez, y "clase social de origen", ninguna. La sociología se ha centrado en el análisis de otras variables, dejando el origen social en un segundo plano.

La segunda causa que explica la desatención al efecto del origen social en el paro, esta vez en los análisis internacionales, es que la tasa de paro en los peores momentos de las fases recesivas no supera el $10 \%$ en los países más importantes del centro y del norte de Europa, y el $9 \%$ en Estados Unidos ${ }^{1}$. En las fases alcistas, el paro en esos mismos lugares no suele superar el $5 \%^{2}$. Se trata de los países con mayor producción sociológica de alto impacto. De ahí que los estudiosos de la estratificación, aunque tengan en cuenta el origen social, hayan centrado sus esfuerzos en otros aspectos del mercado laboral en que la desigualdad tiene más recorrido, como los ingresos o el tipo de ocupación en el que se trabaja, más que en si se tiene o no un empleo.

A nivel nacional, en cambio, la tasa de paro es mucho mayor que en los países citados y, salvo excepciones que veremos más adelante, tampoco abundan los análisis que relacionan el origen social con el paro. Esto puede deberse a que la gran mayoría de las bases de datos en España no contienen información sobre la ocupación de los padres o, si la tienen, suele ser muy limitada y con muestras muy pequeñas, por lo que se torna muy difícil analizar la influencia del origen social sobre cualquier ámbito. Afortunadamente, durante algunos años el Centro de Investigaciones Sociológicas (CIS) ha tratado de cubrir ese hueco en los estudios sobre la estratificación social incluyendo la profesión del padre y de la madre de los entrevistados en todos sus barómetros mensuales, de lo cual se aprovecha este análisis.

El presente artículo apuesta por recuperar la relevancia del origen social analizando su posible influencia en un tema tan grave como el desempleo. El primer objetivo, el más inmediato, es averiguar si el origen social, medido a través del tipo de ocupación de los padres, importa para evitar el paro. En segundo lugar, se pretende analizar si, en caso de que el origen social afecte al paro, se trata de una influencia mediada a través de la educación o si la influencia se mantiene incluso comparando a individuos que tienen el mismo nivel de estudios. De este modo, se trata de comprobar si la versión débil de la meritocracia basada en la educación se cumple. Esta versión de la meritocracia supone que, si se comparan individuos con el mismo nivel educativo, el origen social no debe influir en la posición en el mercado laboral. En tercer lugar, el artículo pretende dirimir si el origen social importa más o menos en función del nivel educativo que se tenga. Es decir, si, tal y como predicen varias teorías que se verán más adelante, el origen social no tiene ningún efecto en el mercado laboral para los que logran un nivel educativo alto, pero sí para los que tienen niveles de estudio bajos.

Estas cuestiones son relevantes por los siguientes motivos. En primer lugar, porque por un lado abundan los análisis que analizan el desempleo, pero no los que investigan cómo le afecta el origen social; y, por otro, porque los que han analizado los efectos del origen social en el mercado laboral no se han centrado en el desempleo. Por lo tanto, existe un hueco en la literatura sociológica con respecto a este tema. Conviene subrayar que, aunque las desigualdades de ingresos o de ocupación son fundamentales y marcan la vida de los individuos, estar parado es la peor situación en la que se puede encontrar una persona económicamente activa y, además, tiene consecuencias insoslayables. A los efectos inmediatos sobre los ingresos y el consumo hay que añadir las cicatrices que deja a medio y largo plazo: los parados tienen una mayor probabilidad de entrar en una espiral de inestabilidad laboral (Cooper 2014; Gangl 2006). A ello hay que sumar otras consecuencias que atañen a su bienestar psicológico (Krueger y Mueller 2011) y al de sus propias familias (Bubonya, Cobb-Clarck y Wooden 2014; Ström 2003). Si hay indicios de que la desigualdad por origen social afecta tanto en el mercado laboral en aspectos como los ingresos o el tipo de ocupación que se tiene, parece razonable entonces explorar sus posibles conexiones con un aspecto tan importante como el paro. 
Otra de las razones por las que este estudio es muy pertinente atañe al país que se analiza, España, un lugar cuyas tasas de paro alcanzan a una proporción muy elevada de la población activa. A diferencia de la gran mayoría de los otros países avanzados, en España el paro está tan extendido que las posibles desigualdades en función del origen social pueden tener un amplio recorrido, por lo que conviene analizar el tema.

A estas razones hay que añadir que el segundo y el tercer objetivo de este análisis llenan un vacío que entronca directamente con teorías sociológicas relevantes. El segundo objetivo, el de saber si el origen social influye en evitar el paro incluso en individuos con los mismos niveles educativos, pretende dilucidar si se cumple una de las premisas de las teorías meritocráticas de las sociedades postindustriales: que la educación es el gran mecanismo que desactiva la influencia del origen social en el empleo.

El tercer objetivo, el de saber si el efecto del origen social varía para cada nivel educativo, intenta profundizar en dos descubrimientos hallados sobre el efecto del origen social en el mercado laboral en función del nivel de estudios de los individuos. Tales descubrimientos han promovido la elaboración de diversas teorías en la estratificación social. Uno de los hallazgos indica que los efectos del origen social quedan anulados una vez que se posee un título universitario. De este modo, si se alcanza dicho título, los individuos procedentes de la clase obrera se liberarían del peso de su origen social para situarse en el mercado laboral. Más recientemente, se ha desarrollado la teoría de las ventajas compensatorias, que señala que el origen social importa sobre todo en individuos con bajos niveles educativos. De este modo, el origen social compensaría los bajos niveles de estudio para los vástagos de las clases sociales profesionales que no logran títulos educativos altos. El origen social les serviría como un empujón para no estar demasiado mal en el mercado laboral, a pesar de sus bajos niveles de estudio. Esta investigación dirime si estos fenómenos también se dan en un ámbito tan importante como el paro, aspecto que prácticamente no se ha analizado hasta ahora. La siguiente sección desarrolla este marco teórico, las hipótesis y resume lo que se sabe hasta ahora.

\section{HIPÓTESIS E INVESTIGACIONES PREVIAS}

\section{La influencia del origen social en el mercado laboral}

Las teorías clásicas de la sociedad postindustrial vaticinaron el tránsito de unas sociedades adscriptivas a otras plenamente adquisitivas. Esto es, el paso de unas sociedades en que las características que están fuera del control de los individuos, como el sexo o el origen social, son importantes para situarse en el sistema de estratificación, a otras en que rige el mérito personal: "La sociedad postindustrial, en su lógica inicial, es una meritocracia. Las diferencias de status e ingresos se basan en las aptitudes técnicas y la educación superior. Sin esos rasgos, uno no puede satisfacer los requisitos de la nueva división social del trabajo" (Bell 1976: 469).

Detrás de este planteamiento se encuentra la idea de que, en el libre mercado, los empresarios están obligados a contratar a los trabajadores que consideran más productivos para no ser engullidos por la competencia. De este modo, a la hora de elegir al mejor candidato para un puesto, se guiarían en función de la educación y no de otras características como el sexo, la nacionalidad o el origen social de los individuos. El paso a las sociedades postindustriales favorecería este hecho a través de diversos mecanismos (Ganzeboom y Treiman 2007). Por una parte, las sociedades postindustriales generan empleos que requieren una mayor cualificación. También aumenta el tamaño de las empresas, con la consecuente burocratización del reclutamiento y de la promoción, guiadas en mayor medida por las credenciales educativas. La mayor movilidad geográfica y la expansión de la ideología igualitaria serían otros dos mecanismos que facilitan la meritocracia.

Si esto fuera así, la educación cumpliría la función de nivelar socialmente a los individuos que han logrado el mismo nivel educativo, al menos en lo que respecta al mercado laboral. Dicho de otro modo: si dos individuos tienen el mismo nivel de estudios, las características adscriptivas como el origen social no deberían importar para posicionarse en el mercado laboral. Algunos han denominado esta visión como la versión débil de la meritocracia basada en la educación (Bernardi y Ballarino 2016b), porque mide la meritocracia en el mercado laboral una vez que se ha logrado un nivel educativo dado, en contraposición con la versión fuerte de la meritocracia, que considera necesario analizar también si el origen social influye o no en tener un nivel educativo u otro (Goldthorpe 2003).

De este modo, los análisis que comprueban la influencia del origen social en el mercado laboral consideran que el origen social tiene una influencia directa si, en caso de que se comparen a individuos con el mismo nivel educativo, el origen social sigue influyendo en la variable dependiente que se trate (bien sea la ocupación, los ingresos o, en este análisis, el paro). La primera hipótesis de este trabajo se centra en la versión débil de la meritocracia basada en la educación y señala que, si la educación es el gran mecanismo que iguala las oportunidades laborales, el origen social no debería importar para estar en el paro una vez que se controla por el nivel educativo de los individuos (hipótesis 1).

La mayor parte de las investigaciones llevadas a cabo desde la sociología han limitado el optimismo de la llegada de una sociedad plenamente meritocrática. 
Se ha demostrado que sigue habiendo una transmisión directa entre el origen social y el tipo de ocupación que uno logra (Hällsten 2013; Triventi 2013; Mastekaasa 2011; Bukodi y Goldthorpe 2011; Goldthorpe y Jackson 2008; Goldthorpe y Mills 2008; Vallet 2004; Bernardi 2003). Estos hallazgos son robustos en distintos países y con diversos métodos. Bernardi y Ballarino (2016c) han coordinado un estudio para catorce países con variables y medidas comparables. Sus resultados corroboran la idea de que la meritocracia plena no se ha alcanzado: en todos los países analizados hay un efecto del origen social sobre la posición en el mercado laboral. Este efecto disminuye entre un 50 y un $75 \%$ cuando se controla por el nivel educativo; pero no desaparece completamente.

En un país con un mercado laboral caracterizado por su alta tasa de paro, como España, se ha encontrado un efecto directo notable entre el origen social y el estatus socioeconómico, los ingresos individuales y los ingresos del hogar (Bernardi y Ares Abade 2017; Bernardi 2016). Otros estudios llevados a cabo con datos más antiguos encontraron un efecto directo moderado entre el origen social y el logro de estatus (Echevarría 1999; Rodríguez Menés 1993; Carabaña 1983), y una disminución de dicho efecto entre generaciones (Carabaña 1999). Por otra parte, también se ha demostrado un efecto directo entre el origen social y la probabilidad de estar sobrecualificado (Marqués Perales y Gil-Hernández 2015; Martínez García 2014).

No obstante, todos esos estudios se han centrado en los ingresos o en el tipo de ocupación que se tiene. Tan solo Blaskó y Róbert (2007) y Carabaña (2000) incluyeron como variable dependiente estar o no en el paro. En el caso de los primeros, su análisis se circunscribe a Hungría y abarca solo a los recién graduados. Concluyeron que el origen social no influía en la probabilidad de que los varones estuvieran en el paro; pero sí influía en las mujeres. En concreto, la probabilidad de que las hijas de las clases más aventajadas sufrieran el paro en los primeros años tras su graduación era un $40 \%$ menor que la de las hijas de las clases menos aventajadas.

En España, con datos de los años ochenta, Carabaña (2000) concluyó que el origen social influía en el tiempo que se tardaba en lograr el primer empleo solo para los hijos de los directivos y empresarios, cuya característica principal es que pueden contratar directamente. Los hijos de estos dos colectivos tardaban menos en encontrar el primer empleo. Otra de sus conclusiones es que no existía relación entre el origen social y el paro sufrido por aquellos que ya habían tenido algún empleo.

Así pues, la mayoría de las investigaciones han hallado una influencia del origen social en el mercado laboral incluso controlando por el nivel educativo. La sociología ha establecido algunas posibles explicaciones sobre esto, al plantear los mecanis- mos que lo hacen posible (Erikson y Jonsson 1998; Hällsten 2013; Passaretta et al. 2018). En el caso de la educación superior, puede que los hijos de las clases más pudientes cursen sus estudios en instituciones o en carreras de mayor prestigio que los universitarios de clase obrera, lo que les daría una ventaja adicional en el mercado de trabajo. También se ha planteado la idea de que los miembros de la clase alta transmitan a sus hijos habilidades cognitivas y no cognitivas más allá de la educación formal, que luego se reflejan en el mercado laboral. En este sentido, Goldthorpe (2010) habla de los soft skills, habilidades sociales importantes para ciertos empleos, como la confianza en uno mismo, la capacidad para presentarse y caer bien, o incluso la perseverancia. En relación con los soft skills, Hakim (2010; 2012) puso de relieve la importancia del capital erótico - una mezcla de atractivo físico y social- en el mercado laboral. Si esas habilidades o características estuvieran desigualmente distribuidas en función del origen social e influyeran a su vez en la posición en el mercado laboral, serían mecanismos a través de los cuales el origen social seguiría importando en el mercado laboral incluso entre individuos con los mismos estudios.

Otro de los mecanismos por los cuales el origen social puede afectar directamente a la situación en el empleo son las distintas redes sociales que tienen las diferentes clases. Los contactos pueden facilitar el empleo o la información clave para obtener uno. Por otra parte, la herencia directa del negocio familiar o un empleo en el mismo, así como las distintas aspiraciones que se moldean desde la infancia, constituyen otros mecanismos a través de los cuales el origen social puede influir en la situación en el mercado laboral. Asimismo, los recursos económicos de la familia de origen también pueden ser relevantes como mecanismos que explicarían la posible influencia del origen social en el mundo del empleo. Por ejemplo, aquellos con más recursos tienen una mayor facilidad para mudarse a lugares con mejores oportunidades laborales. Por último, tampoco hay que descartar la posibilidad de que, para algunos empleos, los empresarios discriminen en función del origen social de los posibles candidatos a un puesto.

\section{¿Influye el origen social de la misma manera en los diferentes niveles educativos?}

Otra de las cuestiones debatibles en este artículo plantea si el origen social influye de la misma manera en los individuos con diferentes niveles educativos. En una investigación seminal llevada a cabo en Estados Unidos en los años ochenta, se comprobó que el origen social no afectaba a la posición laboral de los universitarios (Hout 1988). Se han ofrecido tres tipos de explicaciones a este fenómeno. Por una parte, se argumenta que el mercado laboral de los universitarios se rige por criterios meritocráticos, 
cosa que no sucede tanto con los segmentos del mercado en que se insertan los individuos con niveles de estudio inferiores (Breen y Jonsson 2007). También se ha planteado la posibilidad de que, en realidad, aquellos cuyo origen social es más humilde que llegan a la universidad están seleccionados positivamente en términos de inteligencia y motivación (Mare 1993), aunque cabe mencionar que los análisis más recientes llevados a cabo en Estados Unidos no corroboran esta hipótesis (Karlson 2019). Existe una tercera explicación adicional: que los graduados universitarios acceden al mercado laboral a edades más avanzadas $\mathrm{y}$, cuando comienzan a trabajar, hace años que abandonaron el hogar paterno, ya que estudiaron en una ciudad o región diferente. Esta distancia temporal y física con el hogar de los padres haría que el origen social perdiera influencia a la hora de posicionarse en el mundo del empleo (Müller y Karle 1993).

El hallazgo de Hout sigue inspirando investigaciones que tratan de comprobar si, en efecto, tener un título universitario garantiza el cumplimiento de la versión débil de la meritocracia basada en la educación, al menos en lo que atañe a la relación entre el origen social y el mercado laboral (Mastekaasa 2011; Torche 2011). En un estudio sobre los Licenciados en Ciencias Sociales (CC.SS.) y Humanidades de la Complutense, Carabaña y de la Fuente (2016) hallaron una fuerte influencia del origen social en la probabilidad de trabajar en una ocupación profesional; pero la mayor parte de esa influencia era indirecta, es decir, que los hijos de profesionales eligen las carreras con mejores perspectivas laborales.

En los últimos años se han publicado una serie de análisis complementarios al hallazgo de Hout y a las investigaciones que le siguieron. Estos nuevos análisis, en lugar de centrase en la parte alta del sistema educativo, se han fijado en la parte baja y media. Sus autores han retomado la noción clásica de las ventajas compensatorias, según la cual las familias más aventajadas ponen los medios necesarios para que sus retoños accedan a una buena posición en el mercado laboral en caso de que no obtengan altos niveles educativos (Bernardi y Ballarino 2016c).

Los análisis más recientes con el tipo de ocupación como variable dependiente indican que el efecto directo del origen social se da entre los menos educados, lo que corrobora la idea de las ventajas compensatorias. En el estudio internacional de Bernardi y Ballarino con catorce países, tan solo en Holanda se encontró un efecto directo del origen social mayor entre los universitarios en comparación con los individuos con niveles de estudio bajos o intermedios (Tolsma y Wolbers 2016). En Estados Unidos se ha hallado un patrón en forma de $U$, con un efecto mayor entre los menos educados y los muy educados, los que tienen un postgrado (Torche $2011 ; 2016$ ), un patrón parecido al de Hungría (Keller y Róbert 2016).
Estos mismos análisis también han sido aplicados para estudiar los ingresos. En este caso, el efecto directo del origen social se da más entre los universitarios en la mayoría de los países. Bernardi y BaIlarino (2016b) interpretan que estos dos efectos, el que impulsa a los universitarios hijos de la clase alta a ganar más dinero y el que compensa a los que no logran un alto nivel educativo evitando los peores empleos, son compatibles. Por una parte, las familias aventajadas utilizan una estrategia defensiva con los vástagos que no logran altos niveles educativos para que alcancen así una ocupación al menos cercana a la de sus padres; $y$, por otra, una estrategia ofensiva con los que tienen altos estudios, que maximizan sus ingresos gracias a su origen social. En cambio, otra investigación con datos españoles halló que el origen social no tiene influencia en los salarios de los universitarios (Fachelli, Torrents y Navarro-Cendejas 2014).

Pese a que, como se ha visto, se ha hecho un esfuerzo investigador importante, poco se sabe sobre si el efecto del origen social varía por niveles educativos para estar en el paro. El único indicio con el paro como variable dependiente se encuentra en Fachelli y Navarro-Cendejas (2015) que, con datos para los universitarios catalanes, concluyen que no hay un efecto directo del origen social sobre el desempleo. El presente artículo trata de llenar este vacío en la literatura sociológica. De acuerdo con estas teorías y con los hallazgos derivados de las investigaciones que han estudiado el efecto del origen social sobre otras variables dependientes relacionadas con la posición de los individuos en el mercado laboral, la segunda hipótesis del artículo se centra en la parte alta del sistema educativo. Si en España los títulos universitarios anulan el efecto del origen social, este no debería influir en la probabilidad de estar en el paro para los individuos que poseen dichos títulos. Por su parte, la tercera hipótesis, complementaria de la segunda, se centra en la noción de las ventajas compensatorias y establece que, entre los individuos con niveles educativos bajos, la probabilidad de estar parado será menor entre los hijos de aquellos con un mayor estatus socioeconómico.

\section{Datos, métodos y variables}

Los datos utilizados provienen del CIS. Cada mes (excepto en agosto) publica un barómetro sobre diversos temas con una muestra representativa de 2.500 españoles. Desde febrero de 2013 hasta junio de 2017, estas encuestas incluían como variable sociodemográfica fija la ocupación del padre y de la madre cuando el entrevistado tenía 16 años ${ }^{3}$. Así pues, los investigadores disponen de una información fundamental sobre el origen social que abarca dicho período. Además de esa variable, los barómetros siempre incluyen información sobre el nivel de estudios y la situación laboral de los entrevistados. 
Es importante tener en cuenta que se trata del período de salida de la crisis; un período, en cualquier caso, con tasas de paro muy elevadas (del $26,9 \%$ en el primer trimestre de 2013 hasta un mínimo del 16,4 $\%$ en el tercero de 2017, según la Encuesta de Población Activa (EPA). Esto hace que el caso español sea de los más interesantes del mundo para estudiar este fenómeno.

Dado que algunas de las hipótesis implican interacciones entre variables $y$, como veremos, una desagregación de los niveles de estudios superiores lo más amplia posible, se ha optado por utilizar todas las encuestas existentes con la información del origen social hasta el momento del análisis para aumentar el número de casos. En concreto, se han unido 49 barómetros, desde la encuesta 2978 del CIS (febrero de 2013) hasta la 3187 (septiembre de 2017). De este modo, se dispone de información de 71763 personas económicamente activas (ocupadas o paradas), mayores de edad. El único criterio para seleccionar la muestra ha sido la condición de ser económicamente activo, ya que ser activo es un requisito para estar parado. Como es sabido, los inactivos suelen ser estudiantes jóvenes, jubilados y amas de casa. Con respecto a la edad, no se ha puesto un límite superior más que el marcado por la condición de económicamente activo, ya que el efecto del origen social puede ser muy duradero en el tiempo y no se circunscribe a la entrada en el mercado laboral, tal y como lo atestiguan los análisis citados en el apartado anterior. En los resultados y en el apéndice se ofrecen datos de análisis detallados por grupos de edad para observar los posibles efectos diferenciales del origen social sobre el paro en función de dichos grupos. Tampoco se ha puesto un límite inferior al de los 18 años, edad marcada por las encuestas.

La muestra original contenía 76728 individuos activos. La selección final de algo más de 71763 casos se debe fundamentalmente a que en 4843 no existe ninguna información sobre la ocupación del padre o de la madre cuando el entrevistado tenía 16 años. Eso supone la pérdida de un $6,3 \%$ de la muestra. Se trata de una pérdida relativamente lógica, teniendo en cuenta que se trata de una información difícil de recopilar por parte de los entrevistadores y que escasea mucho en España. Por lo demás, se desconoce el nivel educativo de 141 casos y la edad de cinco entrevistados. No hay casos perdidos en las otras variables introducidas en el análisis: ni en el sexo ni, lógicamente, en el año de la encuesta

La variable dependiente para contrastar las hipótesis es estar en el paro o estar ocupado. La variable independiente clave es el origen social. Tal y como se ha comentado, para ello se dispone de la ocupación del padre y de la madre cuando el entrevistado tenía 16 años. No se dispone, en cambio, de información acerca de si los padres trabajaban por cuenta propia o ajena, lo que impide construir con detalle una clasificación de clases sociales. Por ello, se ha optado por utilizar el índice ISEI (International Socioeconomic Index), que mide el estatus socioeconómico a partir de las ocupaciones (Ganzeboom y Treiman 1996). Para construir el índice, se ha manejado la sintaxis creada por Bernardi y Ares Abade (2017). Este índice varía en las encuestas utilizadas entre los 11,74 puntos (peones agrícolas) y los 88,70 (médicos). Se ha tomado como origen social el índice ISEI más alto de la ocupación del padre o de la madre del entrevistado.

Otra de las variables clave es la educación. Es muy importante desglosar todo lo posible los niveles educativos altos, ya que, de lo contrario el efecto directo del origen social en la posición en el mercado laboral podría sobreestimarse (Carabaña y de la Fuente 2016). Esto sucedería si los individuos cuya procedencia social más aventajada se concentraran en mayor medida en campos de estudio - no niveles - con un mayor rendimiento en el mercado laboral, por ejemplo, las ingenierías (Bernardi y Ares Abade 2017).

Los datos del CIS permiten desglosar los estudios universitarios con suficiente detalle como para, al menos, distinguir entre ciertos niveles y campos de estudio, así que los datos se han desagregado todo lo posible para evitar el sesgo mencionado en el párrafo anterior. Con respecto a los niveles de estudio inferiores, aunque se han realizado análisis por separado para cada nivel, finalmente se ha decidido agrupar a los que tienen menos de la secundaria inicial en una sola categoría para dotar al análisis de mayor consistencia estadística, imposible de lograr con análisis más desagregados, dada la escasez de casos para esos niveles (Ios análisis implican interacción entre variables). De este modo, se ha trabajado finalmente con doce niveles educativos: 1) menos de secundaria inicial; 2) secundaria inicial; 3) Formación Profesional (FP) de grado medio; 4) bachillerato; 5) FP de grado superior; 6 ) arquitectura o ingeniería técnica; 7) diplomatura, 8) licenciatura o grado; 9) arquitectura o ingeniería Superior; 10) máster oficial; 11) doctorado; y 12) títulos propios de postgrado.

Además de la variable relativa al ISEI de los padres, se han añadido como variables de control los años de la encuesta para controlar el efecto período, así como la edad y el sexo del entrevistado. En el apéndice se muestran resultados complementarios en función de la edad y del sexo del entrevistado con el fin de ver si los patrones descubiertos a lo largo del artículo varían en función de dichas variables.

La técnica utilizada es un modelo de probabilidad lineal con errores estándar robustos. Pese a que la variable dependiente es dicotómica (estar o no en el paro), se ha aplicado un modelo lineal, ya que la interpretación de los coeficientes es más sencilla e intuitiva que las odds ratio propias de una regresión logística. Además, a diferencia de otras técnicas no lineales, 
es posible comparar los coeficientes entre distintos modelos, cuestión especialmente importante en este artículo (Mood 2010). Este tipo de modelos se aplica cada vez más a variables dicotómicas por dichas razones (Breen, Karlson y Holm 2018). Con respecto a los datos manejados en este análisis, se ha comprobado que el $75 \%$ de las probabilidades predichas están en el rango de entre 0,28 y 0,64 , dependiendo de los modelos. De 71763 casos, ninguna probabilidad predicha queda por encima del 1, y el modelo en que se dan más probabilidades predichas por debajo de cero incluye 46 casos, alcanzado una probabilidad de $-0,05$ en el peor de ellos. Esos 46 casos suponen el $0,06 \%$ de la muestra. Todo ello hace plausible aplicar un modelo lineal en lugar de uno no lineal (Hippel 2015). La tabla 1 presenta la distribución y algunos estadísticos descriptivos de las variables utilizadas.

\section{RESULTADOS}

La tabla 2 refleja los resultados del modelo de probabilidad lineal sobre la probabilidad de estar en el paro. En el primer modelo, el origen social solo se controla por el año de la encuesta, la edad y el sexo del entrevistado, no por la educación. El modelo muestra que, cuanto más alto sea el origen social, menor probabilidad hay de estar en el paro. El gráfico 1 facilita la interpretación del coeficiente. En el gráfico izquierdo, sin controlar por la educación, se puede ver que el efecto del origen social sobre el paro es muy notable. El hijo de un médico tiene una probabilidad predicha de estar parado de alrededor del $17 \%$; mientras que el hijo de un peón agrario, de algo más del $40 \%$. Se trata de comparaciones extremas, pero reveladoras. Con respecto a las variables de control, la probabilidad de estar en el paro es menor conforme los años se alejan de la crisis (11 puntos menor en 2017 que en 2013) y mayor conforme menos edad se tiene (la probabilidad de estar en el paro para los menores de 30 años es en torno a 13 puntos mayor que los que tienen más edad).

¿Qué sucede cuando las personas de distintos orígenes sociales tienen el mismo nivel de estudios? ¿Es la educación el mecanismo que sirve para anular el efecto del origen social? El modelo 2 controla por los niveles educativos. Como se ve en los coeficientes, el efecto del origen social disminuye muchísimo. Redondeando, el coeficiente del ISEI de los padres baja de $-0,0029$ a $-0,00049$, lo que supone una reducción del $83 \%$ del efecto del origen social. No obstante, dicho efecto sigue siendo significativo. La parte derecha del gráfico 1 representa el efecto del origen social controlando por la educación. La pendiente es mucho menos pronunciada que la del modelo que no controla por dicha variable (parte izquierda del gráfico). En este caso, si comparamos la probabilidad de estar en el paro de dos individuos con el mismo nivel educativo, la probabilidad de estar en el paro para el hijo de un peón agrario es de en torno al $35 \%$; mientras que la del hijo de un médico,
Tabla 1.

Descripción de las variables introducidas en el análisis multivariable.

\begin{tabular}{|c|c|c|}
\hline Variables & casos & $\%$ \\
\hline \multicolumn{3}{|l|}{ Año } \\
\hline 2013 & 14.987 & 20,9 \\
\hline 2014 & 16.261 & 22,7 \\
\hline 2015 & 16.132 & 22,5 \\
\hline 2016 & 14.351 & 20,0 \\
\hline 2017 & 10.032 & 14,0 \\
\hline Suma & 71.763 & 100 \\
\hline \multicolumn{3}{|l|}{ Edad } \\
\hline $18-29$ & 12.846 & 17,9 \\
\hline $30-39$ & 19.956 & 27,8 \\
\hline $40-49$ & 20.316 & 28,3 \\
\hline $50-59$ & 14.818 & 20,7 \\
\hline 60 o más & 3.827 & 5,3 \\
\hline Suma & 71.763 & 100 \\
\hline \multicolumn{3}{|l|}{ Estudios } \\
\hline Menos de secundaria inicial & 6.565 & 9,2 \\
\hline Secundaria inicial & 20.318 & 28,3 \\
\hline FP media & 6.708 & 9,4 \\
\hline Bachillerato & 9.952 & 13,9 \\
\hline FP superior & 9.367 & 13,1 \\
\hline Arq. o ing. técnica & 1.289 & 1,8 \\
\hline Diplomatura & 5.306 & 7,4 \\
\hline Licenciatura o grado & 9.237 & 12,9 \\
\hline Arq. o ing. superior & 1.221 & 1,7 \\
\hline Máster & 1.111 & 1,6 \\
\hline Doctorado & 550 & 0,8 \\
\hline Tít. prop. post. & 139 & 0,2 \\
\hline Suma & 71.763 & 100 \\
\hline \multicolumn{3}{|l|}{ Sexo } \\
\hline Mujeres & 33.827 & 47,1 \\
\hline Varones & 37.936 & 52,9 \\
\hline Suma & 71.763 & 100 \\
\hline \multicolumn{3}{|l|}{ ISEI padres } \\
\hline Media & 34,9 & \\
\hline Máximo & 88,7 & \\
\hline Mínimo & 11,7 & \\
\hline Percentil 25 & 23,6 & \\
\hline Percentil 50 & 26,6 & \\
\hline Percentil 75 & 43,8 & \\
\hline
\end{tabular}

de en torno al $32 \%$. Como se ha comentado, se trata de una diferencia estadísticamente significativa: los intervalos de confianza de los extremos y de la parte media de la probabilidad de estar en el paro en función del ISEI de los padres (calculados con una confianza del $95 \%$ ) no llegan a tocarse; aunque en términos sustantivos, la magnitud del efecto del origen social controlando por la educación es pequeña. 
Tabla 2.

Modelo de probabilidad lineal. Variable dependiente: estar en el paro.

\begin{tabular}{|c|c|c|c|}
\hline & $\begin{array}{l}\text { M1. } \\
\text { Sin controlar por educación }\end{array}$ & $\begin{array}{l}\text { M2. } \\
\text { Controlando por educación }\end{array}$ & $\begin{array}{l}\text { M3. } \\
\text { Interacción origen social educación }\end{array}$ \\
\hline \multicolumn{4}{|l|}{ Año } \\
\hline \multicolumn{4}{|l|}{2013 (ref.) } \\
\hline \multirow{2}{*}{2014} & $-0,020^{* \star *}$ & $-0,016^{\star \star \star}$ & $-0,016^{\star \star *}$ \\
\hline & $(0,000)$ & $(0,002)$ & $(0,002)$ \\
\hline \multirow{2}{*}{2015} & $-0,046^{\star \star \star}$ & $-0,037^{\star \star \star}$ & $-0,037^{\star \star \star}$ \\
\hline & $(0,000)$ & $(0,000)$ & $(0,000)$ \\
\hline \multirow{2}{*}{2016} & $-0,080^{* \star *}$ & $-0,069^{\star \star \star}$ & $-0,069^{\star \star \star}$ \\
\hline & $(0,000)$ & $(0,000)$ & $(0,000)$ \\
\hline \multirow{2}{*}{2017} & $-0,112^{\star \star \star}$ & $-0,100^{\star \star \star}$ & $-0,100^{* \star *}$ \\
\hline & $(0,000)$ & $(0,000)$ & $(0,000)$ \\
\hline \multicolumn{4}{|l|}{ Edad } \\
\hline \multicolumn{4}{|l|}{$18-29$ (ref.) } \\
\hline \multirow{2}{*}{$30-39$} & $-0,130^{\star \star \star}$ & $-0,101^{\star \star \star}$ & $-0,101^{\star \star \star}$ \\
\hline & $(0,000)$ & $(0,000)$ & $(0,000)$ \\
\hline \multirow{2}{*}{$40-49$} & $-0,135^{\star \star \star}$ & $-0,111^{\star \star \star}$ & $-0,112^{\star \star *}$ \\
\hline & $(0,000)$ & $(0,000)$ & $(0,000)$ \\
\hline \multirow{2}{*}{$50-59$} & $-0,126^{\star \star \star}$ & $-0,129^{\star \star \star}$ & $-0,129^{\star \star *}$ \\
\hline & $(0,000)$ & $(0,000)$ & $(0,000)$ \\
\hline \multirow{2}{*}{60 o más } & $-0,144^{\star \star \star}$ & $-0,185^{\star \star \star}$ & $-0,186^{\star \star \star}$ \\
\hline & $(0,000)$ & $(0,000)$ & $(0,000)$ \\
\hline \multirow{2}{*}{ Mujer } & $0,065^{\star \star *}$ & $0,081^{* \star *}$ & $0,082^{* \star *}$ \\
\hline & $(0,000)$ & $(0,000)$ & $(0,000)$ \\
\hline \multirow{2}{*}{ ISEI padres } & $-0,0029^{* * *}$ & $-0,00049^{* * *}$ & $-0,0009^{\star * *}$ \\
\hline & $(0,000)$ & $(0,000)$ & $(0,001)$ \\
\hline \multicolumn{4}{|l|}{ Nivel de estudios } \\
\hline \multicolumn{4}{|l|}{ Secundaria inicial (ref.) } \\
\hline \multirow{2}{*}{ Primaria, FP1 o menos } & & $0,115^{\star \star \star}$ & $0,157^{* \star *}$ \\
\hline & & $(0,000)$ & $(0,000)$ \\
\hline \multirow{2}{*}{ FP medio } & & $-0,083^{* \star \star}$ & $-0,097^{\star \star \star}$ \\
\hline & & $(0,000)$ & $(0,000)$ \\
\hline \multirow{2}{*}{ Bachillerato } & & $-0,141^{\star \star \star}$ & $-0,161^{\star \star \star}$ \\
\hline & & $(0,000)$ & $(0,000)$ \\
\hline \multirow{2}{*}{ FP superior } & & $-0,161^{\star * *}$ & $-0,195^{\star \star *}$ \\
\hline & & $(0,000)$ & $(0,000)$ \\
\hline \multirow{2}{*}{ Arq. o ing. técnica } & & $-0,216^{\star \star *}$ & $-0,232^{\star \star *}$ \\
\hline & & $(0,000)$ & $(0,000)$ \\
\hline \multirow{2}{*}{ Diplomatura } & & $-0,250^{\star \star \star}$ & $-0,288^{\star \star \star}$ \\
\hline & & $(0,000)$ & $(0,000)$ \\
\hline \multirow{2}{*}{ Licenc. o grado } & & $-0,251^{\star \star \star}$ & $-0,249^{* \star *}$ \\
\hline & & $(0,000)$ & $(0,000)$ \\
\hline \multirow{2}{*}{ Arqu. o ing. superior } & & $-0,254^{\star \star *}$ & $-0,249^{* * *}$ \\
\hline & & $(0,000)$ & $(0,000)$ \\
\hline
\end{tabular}




\begin{tabular}{|c|c|c|c|}
\hline & $\begin{array}{l}\text { M1. } \\
\text { Sin controlar por educación }\end{array}$ & $\begin{array}{l}\text { M2. } \\
\text { Controlando por educación }\end{array}$ & $\begin{array}{l}\text { M3. } \\
\text { Interacción origen social educación }\end{array}$ \\
\hline \multirow{2}{*}{ Máster } & & $-0,240^{* \star *}$ & $-0,239^{\star \star \star}$ \\
\hline & & $(0,000)$ & $(0,000)$ \\
\hline \multirow{2}{*}{ Doctorado } & & $-0,290^{* * *}$ & $-0,338^{* * *}$ \\
\hline & & $(0,000)$ & $(0,000)$ \\
\hline \multirow{2}{*}{ Título propio postgrado } & & $-0,214^{* * *}$ & $-0,355^{* * *}$ \\
\hline & & $(0,000)$ & $(0,000)$ \\
\hline \multicolumn{4}{|l|}{$\begin{array}{l}\text { Interacción ISEI } \\
\text { padres*nivel de } \\
\text { estudios }\end{array}$} \\
\hline \multirow{2}{*}{$\begin{array}{l}\text { Primaria, FP inicial o } \\
\text { menos * ISEI padres }\end{array}$} & & & $-0,0018^{* \star *}$ \\
\hline & & & $(0,004)$ \\
\hline \multirow{2}{*}{ FP medio* ISEI padres } & & & 0,0005 \\
\hline & & & $(0,313)$ \\
\hline \multirow{2}{*}{ Bachillerato* ISEI padres } & & & $0,0007^{*}$ \\
\hline & & & $(0,076)$ \\
\hline \multirow{2}{*}{ FP superior* ISEI padres } & & & $0,0010^{* * *}$ \\
\hline & & & $(0,007)$ \\
\hline \multirow{2}{*}{$\begin{array}{l}\text { Arqu. o ing. técnica * ISEI } \\
\text { padres }\end{array}$} & & & 0,0005 \\
\hline & & & $(0,360)$ \\
\hline \multirow{2}{*}{ Diplomatura* ISEI padres } & & & $0,0011^{* * *}$ \\
\hline & & & $(0,005)$ \\
\hline \multirow{2}{*}{$\begin{array}{l}\text { Licenciatura o grado* } \\
\text { ISEI padres }\end{array}$} & & & 0,0001 \\
\hline & & & $(0,702)$ \\
\hline \multirow{2}{*}{$\begin{array}{l}\text { Arqu. o ing. superior* } \\
\text { ISEI padres }\end{array}$} & & & 0,0001 \\
\hline & & & $(0,834)$ \\
\hline \multirow{2}{*}{ Máster* ISEI padres } & & & 0,0002 \\
\hline & & & $(0,762)$ \\
\hline \multirow{2}{*}{ Doctorado* ISEI padres } & & & $0,0011^{*}$ \\
\hline & & & $(0,084)$ \\
\hline \multirow{2}{*}{ Tít. propio* ISEI padres } & & & $0,003^{*}$ \\
\hline & & & $(0,059)$ \\
\hline \multirow{2}{*}{ Constante } & $0,565^{\star \star *}$ & $0,556^{\star \star \star}$ & $0,568^{* * *}$ \\
\hline & $(0,000)$ & $(0,000)$ & $(0,000)$ \\
\hline Casos & 71.763 & 71.763 & 71.763 \\
\hline R-cuadrado & 0,035 & 0,084 & 0,085 \\
\hline
\end{tabular}

Valores $p$ entre paréntesis.

${ }^{* * *} p<0.01,{ }^{* *} p<0.05,{ }^{*} p<0.1$.

El modelo 2 de la tabla 2 señala que el nivel educativo es mucho más relevante para evitar el paro que la clase social de origen. Como se ha visto, las diferencias para estar en el paro, si comparamos a dos individuos con orígenes sociales extremos que tienen el mismo nivel educativo, es en torno a 3 puntos porcentuales. Para comparar proporciones, según el mismo modelo, la probabilidad de estar en el paro de un bachiller es de 14 puntos menor que la de alguien con secundaria inicial; la de un licenciado o graduado universitario, 25 puntos menor; y la de alguien con un doctorado, 29 puntos menor. Es decir, los estudios importan mucho más que el origen social. 
Gráfico 1.

Probabilidades predichas de estar parado en función del origen social.

\section{G1. Probabilidad de estar en el paro en función del ISEI de los padres}
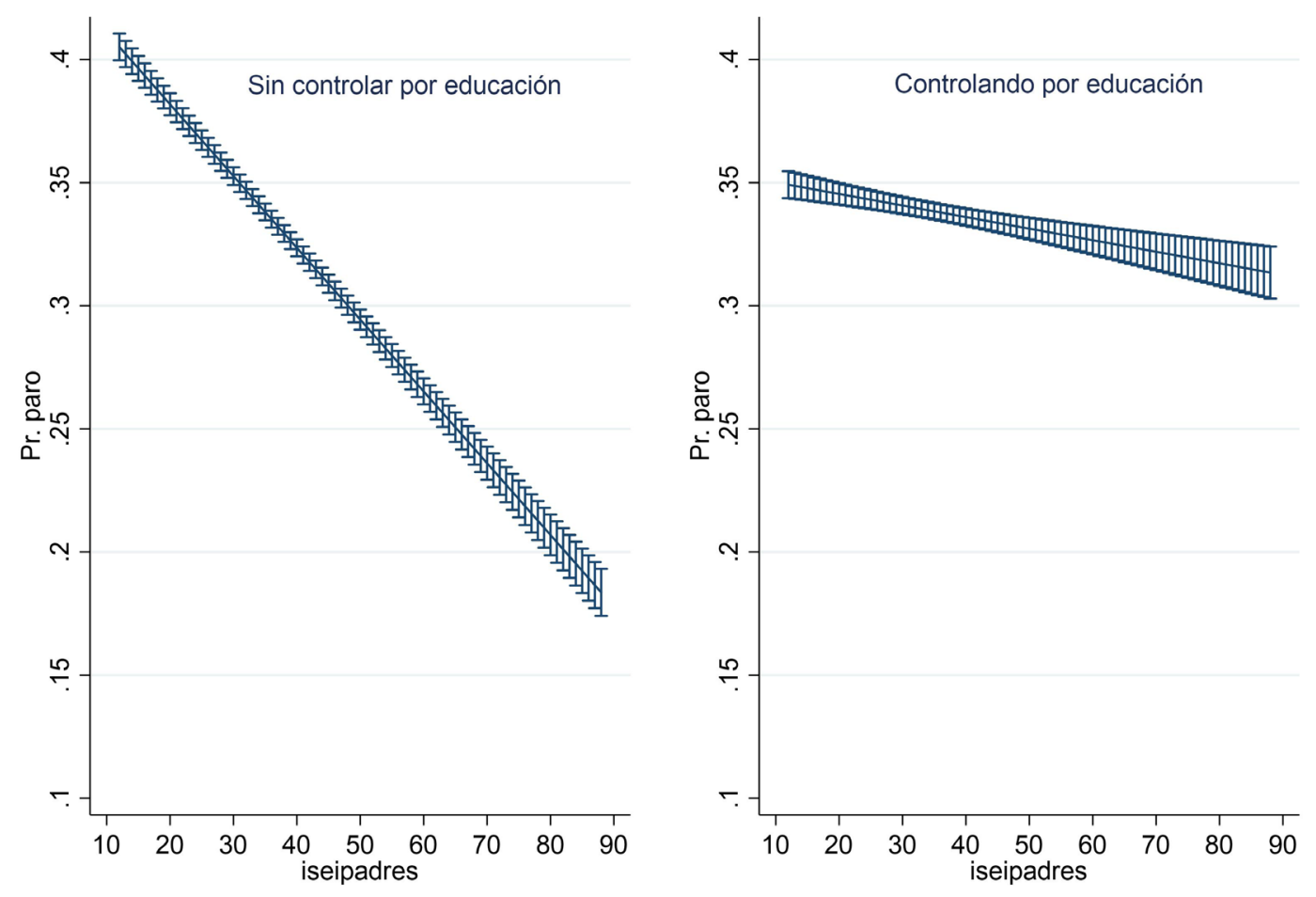

Algunas ocupaciones de la escala ISEI: 12= peones agrícolas; 16=trabajadores cualificados de la agricultura; $25=$ =albañiles y camareros; $29=$ tenderos; $37=$ policías; $51=$ contables; $58=$ =asistentes administrativos; $65=$ directores de empresas de servicios profesionales; 71=profesores de primaria; 79=ingenieros (excepto agrónomos, de montes y eléctricos); 82=profesores de secundaria; 85= jueces, magistrados, abogados y fiscales=85; 89=médicos.

Así pues, los dos primeros modelos de la tabla 1 desvelan que hay un efecto del origen social sobre el paro; pero que la mayor parte de ese efecto es indirecto, esto es, a través de la educación. Los hijos de las clases altas obtienen niveles de estudio menos propensos al paro que los hijos de la clase obrera. Por lo tanto, se corrobora parcialmente la hipótesis 1. A igual nivel de estudios, la clase social de origen sigue teniendo un efecto significativo sobre el paro, aunque pequeño. Con el propósito de que este apartado no se desvíe de las hipótesis planteadas, en el apéndice se detallan las diferencias en la probabilidad de acceder a la universidad en función del origen social y de la cohorte de nacimiento (ver gráfico 4 en el apéndice). Ahí es donde más influye el origen social y donde se centra la teoría fuerte de la meritocracia: la que señala que se debe analizar la probabilidad de tener un nivel de estudios $u$ otro en función del origen social.

Las otras preguntas del artículo tratan de dirimir si el efecto del origen social en el paro varía por niveles de estudios. Si no influyera en los niveles altos, quedaría probado para España que la universidad es un salvoconducto en virtud del cual los individuos de origen so- cial humilde igualan su probabilidad de estar en el paro en comparación con los hijos de las clases profesionales. El modelo 3 de la tabla 2 responde a esta cuestión. Además de controlar por el año de la encuesta, el género y la edad, el modelo presenta interacciones entre el origen social y los niveles educativos.

Interpretar los coeficientes de las interacciones directamente en la tabla es complejo, puesto que hay que tener en cuenta los efectos principales de las variables implicadas en dichas interacciones $y$, además, los coeficientes de las interacciones. Por eso se muestra el gráfico 2, que representa las probabilidades de estar en el paro en función del origen social para los niveles de estudios superiores, los universitarios. Con este gráfico la interpretación es muy sencilla: cuanto más horizontales sean las líneas en cada nivel educativo, menos influye el origen social para estar en el paro. Teniendo en cuenta los intervalos de confianza, podemos decir que, en efecto, si se tiene un título universitario, el origen social no influye en la probabilidad de estar parado. Eso sucede en las arquitecturas o ingenierías, sean técnicas o superiores, y también en las diplomaturas, en los másteres y entre los que tienen el título de doctor ${ }^{4}$. 
No sucede lo mismo con los licenciados o graduados universitarios. En estos casos, el origen social sí tiene alguna influencia, puesto que podemos estar seguros al $95 \%$ de que los hijos de los profesionales (los que tienen un ISEI más alto) tienen una menor probabilidad de sufrir el paro que los hijos de la clase trabajadora (los que tienen el ISEI más bajo). Incluso teniendo en cuenta los intervalos de confianza, las probabilidades predichas de estar en el paro de unos y de otros no se tocan. Por comparar los extremos, la probabilidad predicha de que el licenciado hijo de un peón agrario esté en el paro es alrededor del $22 \%$; mientras que la probabilidad de que lo esté un licenciado hijo de un médico es alrededor del 16 $\%$. De este modo, la hipótesis 2 queda corroborada parcialmente, en todos los niveles superiores con la excepción de los licenciados o graduados universitarios, excepción importante, dado que la mayor parte de los universitarios se concentra en esos estudios. En las conclusiones se discutirán algunos de los mecanismos que pueden explicar este hecho.
El gráfico 3 representa las mismas probabilidades para los niveles de estudio inferiores y medios, lo cual sirve para comprobar la hipótesis 3 , relativa a los efectos de compensación para los hijos de las clases profesionales que no obtienen niveles de estudios altos. En el gráfico se observa que el origen social no influye para estar en el paro entre los que poseen el bachillerato o algún título de FP media o superior. Sí que influye, en cambio, entre los que tienen menos de la secundaria inicial. Así es que, teniendo en cuenta los intervalos de confianza, podemos estar seguros al 95 $\%$ de que los hijos de los profesionales que se quedan con estudios muy bajos tienen una probabilidad de estar en el paro significativamente menor que los hijos de los obreros con sus mismos estudios. La probabilidad de sufrir el paro es alta entre todos los que tienen esos niveles educativos bajos, pero la diferencia entre los de un origen social más alto y más bajo es en torno a los 20 puntos porcentuales (oscila entre los $10 \mathrm{y}$ los 30 puntos, dependiendo de los intervalos de confianza). Algo parecido sucede con los que tienen la

\section{Gráfico 2.}

Probabilidades predichas de estar parado para los niveles educativos superiores. Modelos con interacción entre la educación y el origen social.

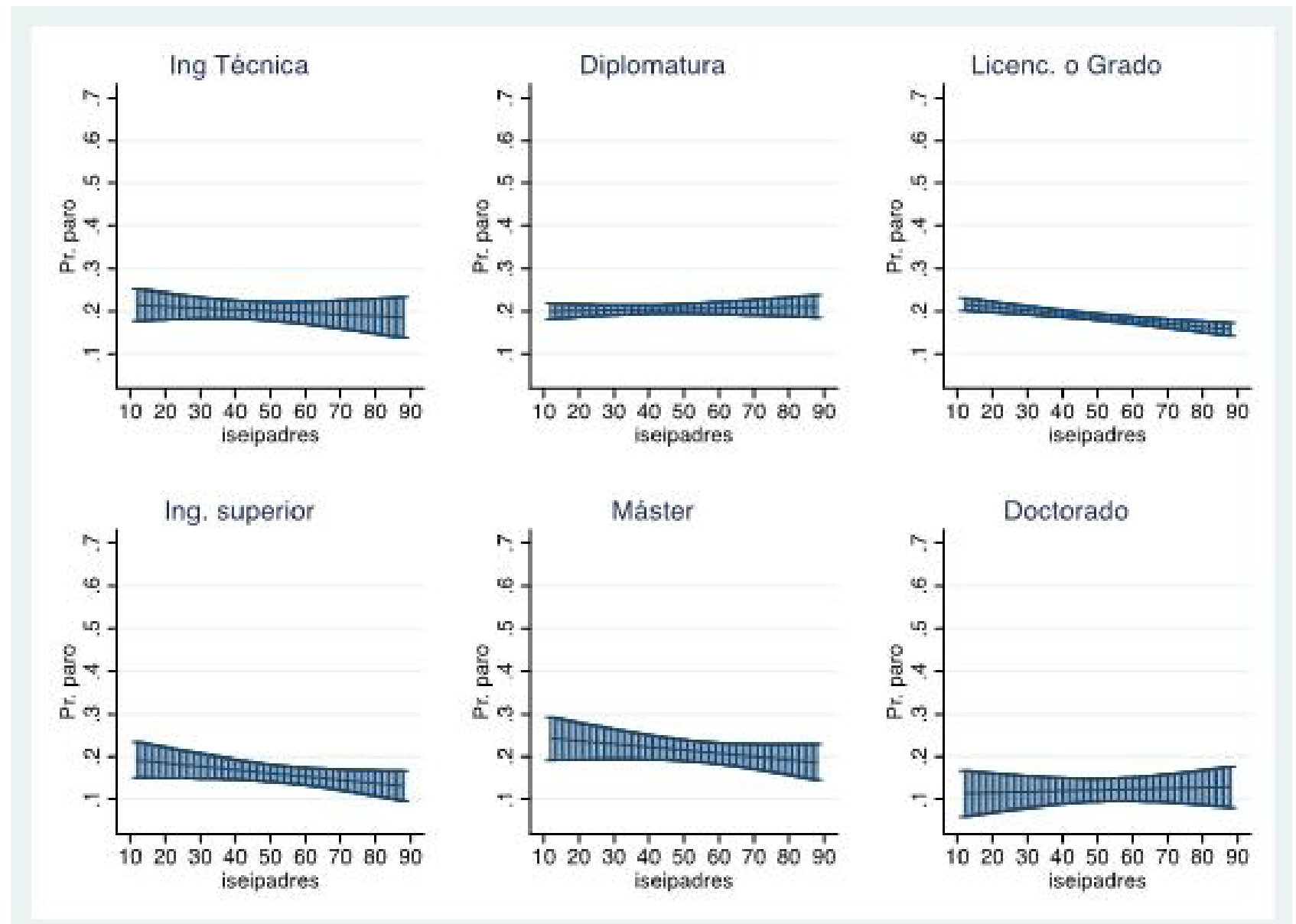

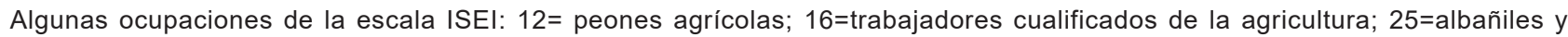
camareros; 29=tenderos; 37=policías; 51=contables; 58=asistentes administrativos; $65=$ directores de empresas de servicios profesionales; $71=$ profesores de primaria; 79=ingenieros (excepto agrónomos, de montes y eléctricos); $82=$ profesores de secundaria; $85=$ jueces, magistrados, abogados y fiscales $=85 ; 89=$ médicos. 
secundaria inicial, aunque las diferencias son mucho menores, en torno a los 6 puntos porcentuales entre los orígenes sociales extremos, distancia que puede aumentar o disminuir moderadamente en función de los intervalos de confianza. Pese a que los resultados han de interpretarse con cautela por las razones que se expondrán en las conclusiones, el hecho de que el origen social influya para evitar el paro en aquellos con niveles educativos inferiores es un indicio de que el efecto de compensación, expuesto en la hipótesis 3, también se da en España en relación con una variable tan fundamental como el paro.

Además de estos análisis, se han realizado otros complementarios a modo de prueba de robustez para comprobar si las tendencias se mantienen por grupos de edad y en función del sexo. En concreto, se han reproducido los análisis del gráfico 1 para ver los efectos del origen social sin controlar por la educación y controlando por ella. Con respecto a la edad, el efecto del origen social sin controlar por la educación es muy parecido en todos los grupos, tanto entre los más jóvenes como entre los mayores (ver el gráfico 5 del apéndice). Las pendientes de las rectas son casi idénticas en todas las edades. En cambio, si se controla por la educación, el efecto negativo del origen social se da solo en los grupos más jóvenes, sobre todo entre los menores de
40 años (ver el gráfico 6 del apéndice). Los modelos (no presentados aquí) muestran diferencias estadísticamente significativas entre los jóvenes y los mayores. Esto puede deberse a que, si se comparan individuos con los mismos estudios, la penalización del origen social bajo se da únicamente en los años cercanos a la entrada en el mercado laboral y no después. Aunque parece menos plausible, con los datos manejados de naturaleza transversal, no es posible descartar la hipótesis de que este fenómeno se deba a un efecto generacional, y no de edad. Esto es, que en las generaciones que tienen más de 40 años la versión débil de la meritocracia basada en la educación se ha cumplido siempre, mientras que, en las generaciones más recientes sabemos que no, al menos hasta la edad que tienen en el momento de la encuesta. Para averiguarlo, lo ideal sería contar con datos longitudinales con los que poder seguir la evolución del efecto del origen social a lo largo del tiempo en distintas cohortes (Passaretta et al. 2018).

Por último, con respecto al efecto del origen social para varones y mujeres, los modelos no muestran diferencias significativas. En el gráfico 7 del apéndice se aprecia que las pendientes de las rectas indican que el efecto del origen social en el paro es idéntico para varones y mujeres sin controlar por educación, y también cuando se controla por esa variable.

Gráfico 3.

Probabilidades predichas de estar parado para los niveles educativos bajos e intermedios. Modelos con interacción entre la educación y el origen social.
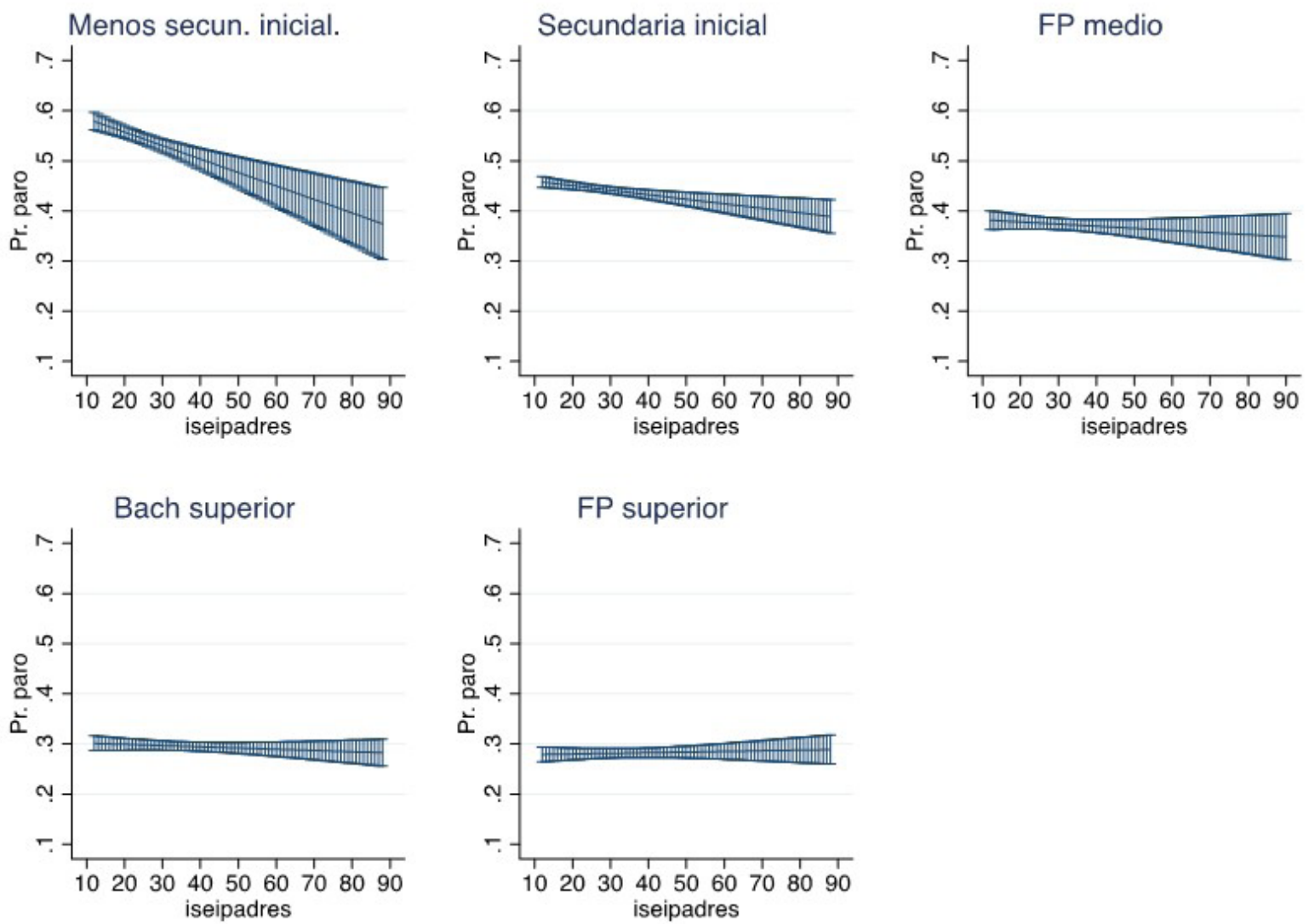


\section{Conclusiones}

Este artículo ha constatado, en primer lugar, que el origen social influye, y mucho, a la hora de sufrir el paro; pero también que la mayor parte de esa influencia está mediada por el nivel educativo. Los hijos de profesionales tienen una alta probabilidad de cursar estudios menos proclives al paro en comparación con los hijos de obreros. Aun así, el efecto del origen social no desaparece por completo si se comparan individuos que poseen el mismo nivel educativo, por lo que el supuesto derivado de la versión débil de la meritocracia basada en la educación no se cumple del todo con respecto al paro.

Otro de los hallazgos es que el efecto del origen social no es idéntico en todos los niveles educativos. Poseer un título universitario anula el efecto del origen social sobre estar parado si se ha estudiado alguna diplomatura, ingeniería, un máster o un doctorado. No sucede lo mismo si se posee alguna licenciatura o algún grado, ya que los hijos de profesionales tienen una ligera menor probabilidad de sufrir el paro que los hijos de obreros. Con respecto a los niveles educativos inferiores, los resultados muestran un efecto compensatorio para los hijos de los profesionales. Para todos los que poseen la educación secundaria inicial o menos, la probabilidad de estar parado es alta; pero es más alta para los que proceden de la clase obrera que para los hijos de los profesionales.

El hecho de que el origen social siga importando en algunos niveles educativos para evitar el paro puede deberse a varios factores que no ha sido posible comprobar en este artículo por la limitación de los datos. Con respecto a las extintas licenciaturas o los nuevos grados, es posible que los hijos de los profesionales elijan carreras con una menor propensión al paro que las carreras elegidas por los hijos de los obreros. Los datos manejados en este artículo permiten distinguir entre distintos niveles universitarios, y entre las ingenierías y el resto de las ramas. Lo ideal hubiera sido disponer de información mucho más detallada, carrera por carrera, para determinar si este factor es relevante, tal y como demostraron Carabaña y de la Fuente (2016) cuando analizaron el tipo de ocupación de los licenciados en la Complutense en Ciencias Sociales y Humanidades. Otro de los posibles mecanismos que puede explicar el hecho de que el origen social influya moderadamente en el paro para los licenciados es el del prestigio de la universidad en que se estudie. Esto sucedería si los hijos de profesionales estudiaran en universidades de mayor prestigio que los hijos de obreros, y si ese hecho influyera a su vez en la probabilidad de ser contratado.
Existen otros mecanismos a través de los cuales el origen social puede incidir en la probabilidad de sufrir el paro incluso entre individuos que tienen el mismo nivel educativo, también entre los que poseen la secundaria inicial o menos. Estos mecanismos, explicados en la sección teórica, son las habilidades cognitivas y no cognitivas (inteligencia, habilidades sociales como caer bien o la confianza en uno mismo), las redes sociales, la propiedad de algún negocio o incluso el capital erótico. De nuevo es necesario remarcar que, para que esos factores fueran decisivos, deberían estar desigualmente repartidos entre los orígenes sociales y, a su vez, influir en la probabilidad de estar parado. Se trata de hipótesis que habrán de comprobarse en futuras investigaciones que dispongan de esas variables. Aunque la versión débil de la meritocracia se centra en la idea de que la educación es el gran igualador social, y este análisis ha demostrado que su premisa no se cumple del todo, es necesario ser cautos a la hora atribuir las diferencias por origen social a la falta de meritocracia, puesto que individuos con los mismos estudios pueden diferir en, por ejemplo, habilidades cognitivas como la inteligencia, o en habilidades sociales, rasgos valorados como meritorios en el mundo del empleo.

Estos hallazgos completan el cuadro sobre el efecto del origen social en la posición que uno ocupa en el mercado laboral en España. Como se ha resumido en el apartado teórico, con los datos más recientes, aunque se comparen individuos con el mismo nivel educativo, los hijos de las clases profesionales ocupan puestos mejores, sufren menos la sobrecualificación y, además, sus salarios son mayores. Esta investigación ha hallado que, con respecto al paro, el efecto del origen social es pequeño una vez que se controla la educación, aunque no desaparece. El artículo también ha demostrado que ser universitario anula en gran parte el efecto del origen social, aunque no del todo para los licenciados o graduados; y que, entre los que poseen la secundaria inicial o menos, tener un origen social alto compensa hasta cierto punto el hecho de tener esos bajos niveles educativos a la hora de sufrir el paro.

\section{Agradecimientos}

Esta investigación ha sido financiada por el Ministerio de Ciencia e Innovación. Proyecto CSO2014-59927-R

\section{ACKNOWLEDGMENTS}

This research was funded by the Spanish Ministry of Science and innovation. Project CSO2014-59927-R 


\section{Notas}

[1] Durante la gran recesión de 2007-2013, la tasa de paro más elevada fue del $10 \%$ en Francia, del $8 \%$ en Alemania, Suecia y Reino Unido, y del $9 \%$ en Estados Unidos (datos de la Organización para la Cooperación y Desarrollo Ecómico, OCDE).

[2] Excepto en Francia, cuya tasa de paro oscila entre el 7 y $9 \%$ en los períodos de bonanza.

[3] Entre febrero de 2013 y junio de 2017 se incluían siempre estas preguntas en los barómetros del CIS. Entre ese mes y junio de 2018, solo en algunos barómetros. Desde junio de 2018 dejaron de incluirse.

[4] En el caso de las ingenierías superiores y de los másteres, los gráficos muestran un ligero efecto del origen social; pero no podemos estar seguros al $95 \%$ de que ese efecto se deba a la muestra, ya que los intervalos de confianza entre los extremos del ISEI llegan a tocarse ampliamente.

\section{REFERENCIAS BibLIOGRÁfiCAS}

Albanesi, S. y A. Sahin. 2018. "The gender unemployment gap". Review of Economic Dynamics 30: 47-67. https:// doi.org/10.1016/j.red.2017.12.005

Bell, D. 1976. El advenimiento de la sociedad postindustrial. Madrid: Alianza.

Bernardi, F. 2003. "Returns to educational performance at entry into the Italian labour market". European Sociological Review 19 (1): 25-40. https://doi.org/10.1093/ esr/19.1.25

Bernardi, F. y M. Ares Abade. 2017. "Education as the (not so) great equalizer: new evidence based on a parental fixed effect analysis for Spain". European University Institute Working Papers, SPS 2017/6.

Bernardi, F. 2016. "Is education the great equalizer for the chances of social mobility in Spain?". Pp. 168-181 en Education, Occupation and Social Origin: A Comparative Analysis of the Transmission of Socio-Economic Inequalities, editado por F. Bernardi y G. Ballarino. Cheltenham: UK: Edward Elgar Publishing. https://doi.org/1 0.4337/9781785360459.00016

Bernardi, F. y G. Ballarino. 2016a. "The intergenerational transmission of inequality and education in fourteen countries: a compassion". Pp. 255-282 en Education, Occupation and Social Origin: A Comparative Analysis of the Transmission of Socio-Economic Inequalities, editado por F. Bernardi y G. Ballarino. Cheltenham: UK: Edward Elgar Publishing. https://doi.org/10.4337/9781 785360459.00021

Bernardi, F. y G. Ballarino. 2016b. "Education as the great equalizer: a theoretical framework". Pp. 1-19 en Education, Occupation and Social Origin: A Comparative Analysis of the Transmission of Socio-Economic Inequalities, editado por F. Bernardi y G. Ballarino. Cheltenham: UK: Edward Elgar Publishing. https://doi.org/1 $0.4337 / 9781785360459.00006$

Bernardi, F. y G. Ballarino (eds.). 2016c. Education, Occupation and Social Origin: A Comparative Analysis of the Transmission of Socio-Economic Inequalities. Cheltenham: UK: Edward Elgar Publishing. https://doi. org/10.4337/9781785360459

Blaskó, Z. \& Róbert, P. (2007). Graduates in the Labour Market: Does Socio-economic Background Have an Impact? The Case of Hungary. Sociologický časopis/ Czech Sociological Review 43 (6): 1149-1173.

Breen, R. y J. O. Jonsson. 2007. "Explaining change in social fluidity: educational equalization and educational expansion in twentieth-century Sweden". American Journal of Sociology 112 (6): 1775-1810. https://doi.org/10.1086/508790

Breen, R., K. B. Karlson and A. Holm. 2018. "Interpreting and understanding logits, probits, and other nonlinear probability models." Annual Review of Sociology 44: 39-54.
Bubonya, M., D. A. Cobb-Clark y M. Wooden. 2014. "A family affair: job loss and the mental health of spouses and adolescents". IZADiscussion Paper No. 8588. https:// doi.org/10.2139/ssrn.2532754

Bukodi, E. y J. Goldthorpe. 2011. "Social class returns to higher education: chances of access to the professional and managerial salariat for men in three British birth cohorts". Longitudinal and Life Course Studies 2 (2): 185-201.

Carabaña, J. 1983. Educación, Ocupación e Ingresos en la España del siglo XX. Madrid: Ministerio de Educación y Ciencia.

Carabaña, J. 1999. Dos Estudios sobre Movilidad Social. Madrid: Fundación Argentaria.

Carabaña, J. 2000. "Títulos contra paro. ¿Protegen los estudios contra el desempleo?". Pp. 515-604 en La formación, clave para el empleo, coordinado por F. Sáez. Madrid: Argentaria-Visor.

Carabaña, J. y G. de la Fuente. 2016. "Facultad por Facultad. Origen familiar y empleo de los licenciados en CCSS y Humanidades de la UCM en el año 2003". Revista Complutense de Educación 27 (3): 983-1001.

Cebolla-Boado, H. M. Miyar-Busto y J. Muñoz-Comet. 2015. "Is the Spanish Recession Increasing Inequality? Male Migrant-native Differences in Educational Returns Against Unemployment". Journal of Ethnic and Migration Studies 41 (5): 710-728. https://doi.org/10.1080/13 69183X.2014.936837

Cooper, D. 2014. "The effect of unemployment duration on future earnings and other outcomes". Federal Reserve Bank of Boston Working Papers, $n^{\circ} 13-8$.

Dustmann C., A. Glitz y T. Vogel. 2010. "Employment, wages, and the economic cycle: differences between immigrants and natives". European Economic Review 54, 1-17. https://doi.org/10.1016/j.euroecorev.2009.04.004

Echevarría, J. 1999. La movilidad social en España, Madrid: Istmo.

Erikson, R. y J. O. Jonsson. 1998. "Social origin as an interest-bearing asset: family background and labourmarket rewards among employees in Sweden". Acta Sociologica, 41 (1), 19-36. https://doi.org/10.1177\% 2F000169939804100102

Fachelli, S. y J. Navarro-Cendejas. 2015. "Relación entre origen social e inserción laboral de los graduados universitarios". Relieve 22 (2): art.2.

Fachelli, S., D. Torrents y J. Navarro-Cendejas. 2014. “¿La universidad española suaviza las diferencias de clase en la inserción laboral?". Revista de Educación 364, 119-144.

Fernández, R. 2013. "Cultural change as learning: the evolution of female labor force participation over a century". 
The American Economic Review 103 (1): 472-500. https://doi.org/10.1257/aer.103.1.472

Gangl, M. 2006. "Scar effects of unemployment: An assessment of institutional complementarities". American Sociological Review 71(6): 986-1013. https://doi. org/10.1177/000312240607100606

Ganzeboom, H. y D. Treiman. 1996. "Internationally comparable measures of occupational status for the 1988 International Standard Classification of Occupations". Social Science Research 25: 201-239. https://doi.org/10.1006/ssre.1996.0010

Ganzeboom, H. y D. Treiman. 2007. "Adscription and achievement in occupational attainment in comparative perspective". Artículo presentado en el Sixth Meeting of the Russell Sage Foundation/Carnegie Corporation UCLA, 25-26 de enero de 2007.

Goldpthorpe, J. H. 2003. "The myth of education-based meritocracy”, New Economy 10 (4): 234-239.

Goldthorpe, J. H. 2010. De la sociología. Números, narrativas e integración de la investigación y la teoría, Madrid, CIS.

Goldthorpe, J.H. y M. Jackson. 2008. "Problems of an education-based Meritocracy. Pp. 93-116 en Social Class: How Does it Work?, editado por A. Lareau y D. Conley. New York: Russell Sage Foundation Press.

Goldthorpe, J. y C. Mills. 2008. "Trends in inter-generational class mobility in modern Britain: evidence from national surveys, 1972-2005". National Institute Economic Review 205: 83-100. https://doi. org/10.1177/0027950108096591

Hakim, C. 2010. "Erotic Capital". European Sociological Review 26(5): 499-518.

Hakim, C. 2012. Capital erótico. El poder de fascinar a los demás. Barcelona: Debate.

Hällsten, M. 2013. "The class-origin wage gap: heterogeneity in education and variations across market segments". British Journal of Sociology 64 (4): 662-690. https:// doi.org/10.1111/1468-4446.12040

Hippel, P. V. 2015. "Linear vs. logistic probability models: Which is better, and when?". https://statisticalhorizons.com/ linear-vs-logistic [Consulta 21 de octubre de 2019].

Hout, M. 1988. "More universalism, less structural mobility: the American occupational structure in the 1980s". American Journal of Sociology 93: 1358-1400. https://doi. org/10.1086/228904

Jacob, M. y C. Kleinert. 2014. "Marriage, Gender and Class: The Effects of Partner Resources on Unemployment Exit in Germany". Social Forces 92 (3): 839-871. https://doi.org/10.1093/sf/sot130

Karlson, K. B. 2019. "College as equalizer? Testing the selectivity hypothesis". Social Science Research, 80, 216229. https://doi.org/10.1016/j.ssresearch.2018.12.001

Keller, T. y P. Róbert. 2016. "Inequality in educational returns in Hungary". Pp 49-64 en Education, Occupation and Social Origin: A Comparative Analysis of the Transmission of Socio-Economic Inequalities, editado por F. Bernardi y G. Ballarino. Cheltenham: UK: Edward Elgar Publishing. https://doi.org/10.4337/9781785360459.00009

Krueger, A. B. y A. Mueller. 2011. "Job search, emotional wellbeing, and job finding in a period of mass unemployment: Evidence from high-frequency longitudinal data". Brookings Papers on Economic Activity 2011(1): 1-57. https://doi.org/10.1353/eca.2011.0001

Mare, R. 1993. "Educational stratification on observed and unobserved components of family background". Pp. 351394, en Persistent Inequality: Changing Educational Attainment in Thirteen Countries, editado por Y. Shavit y H.P. Blossfeld. Boulder, CO: Westview Press.
Marqués Perales, I. y C. J. Gil-Hernández. 2015. "Origen social y sobreeducación de los universitarios españoles: ¿es meritocrático el acceso a la clase de servicio?". Revista Española de Investigaciones Sociológicas 150: 89-112. http://dx.doi.org/10.5477/cis/reis.150.89

Martínez García, J. S. 2014. "Sobrecualificación de los titulados superiores y movilidad social". Pp. 117-140, en PIAAC Programa internacional para la evaluación de las competencias de la población adulta. 2013. Informe español, Vol. II. Madrid: MEC-INEE.

Mastekaasa, A. 2011. "Social origins and labour market success - stability and change over Norwegian birth cohorts 1950-1969". European Sociological Review 27 (1): 1-15. https://doi.org/10.1093/esr/jcp050

Mood, C. 2010. "Logistic regression: Why we cannot do what we think we can do, and what we can do about it." European Sociological Review 26(1): 67-82.

Mooi-Reci, I. y M. Mills. 2012. "The gendered consequences of unemployment insurance reforms". Social Forces 91 (2): 583-608. https://doi.org/10.1093/sf/sos111

Müller, W. y Karle, W. (1993), "Social Selection in Educational Systems in Europe", European Sociological Review 9 (1): 1-23.

Muñoz-Comet, J. 2016. "Potential work experience as protection against unemployment: Does it bring equal benefit to immigrant and native workers?". European Sociological Review 32(5): 537-551. https://doi.org/10.1093/ esr/jcv137

Passaretta, G., P. Barbieri, M. H. J. Wolbers y M. Visser. 2018. "The direct effect of social origin on men's occupational attainment over the early life course: An Italian-Dutch comparison". Research in Social Stratification and Mobility 56: 1-11. https://doi.org/10.1016/j.rssm.2018.04.002

Rodríguez Menés, J. 1993. "Movilidad social y cambio social en España". Revista Española de Investigaciones Sociológicas 61: 77-126.

Ström, S. 2003. "Unemployment and families: A review of research". Social Service Review, 77(3): 399-430. https:// doi.org/10.1086/375791

Tolsma, J. y M. H. J. Wolbers. 2016. "Social origin and inequality in educational returns in the Dutch labour market". Pp. 114-131, en Education, Occupation and Social Origin: A Comparative Analysis of the Transmission of Socio-Economic Inequalities, editado por F. Bernardi y G. Ballarino. Cheltenham: UK: Edward Elgar Publishing. https://doi.org/10.4337/9781785360459.00013

Torche, F. 2011. "Is a college degree still the great equalizer? Intergenerational mobility across levels of schooling in the US". American Journal of Sociology 117 (3): 763807. https://doi.org/10.1086/661904

Torche, F. 2016. "Education and the intergenerational transmission of advantage in the US". Pp. 237-254 en Education, Occupation and Social Origin: A Comparative Analysis of the Transmission of Socio-Economic Inequalities, editado por F. Bernardi y G. Ballarino. Cheltenham: UK: Edward Elgar Publishing. https://doi.org/1 $0.4337 / 9781785360459.00020$

Triventi, M. 2013. "The role of higher education stratification in the reproduction of social inequality in the labor market". Research in Social Stratification and Mobility 32: 45-63. https://doi.org/10.1016/j.rssm.2013.01.003

Vallet, L. A. 2004. "Change in intergenerational class mobility in France from the 1970s to the 1990s and its explanation: an analysis following the CASMIN approach". Pp. 115-147, en Social Mobility in Europe, editado por R. Breen. Oxford: Oxford University Press. https://doi. org/10.1093/0199258457.003.0005 


\section{APÉNDICE}

\section{El origen social influye mucho en tener un título universitario}

\section{Gráfico 4.}

Probabilidades predichas de tener un título universitario

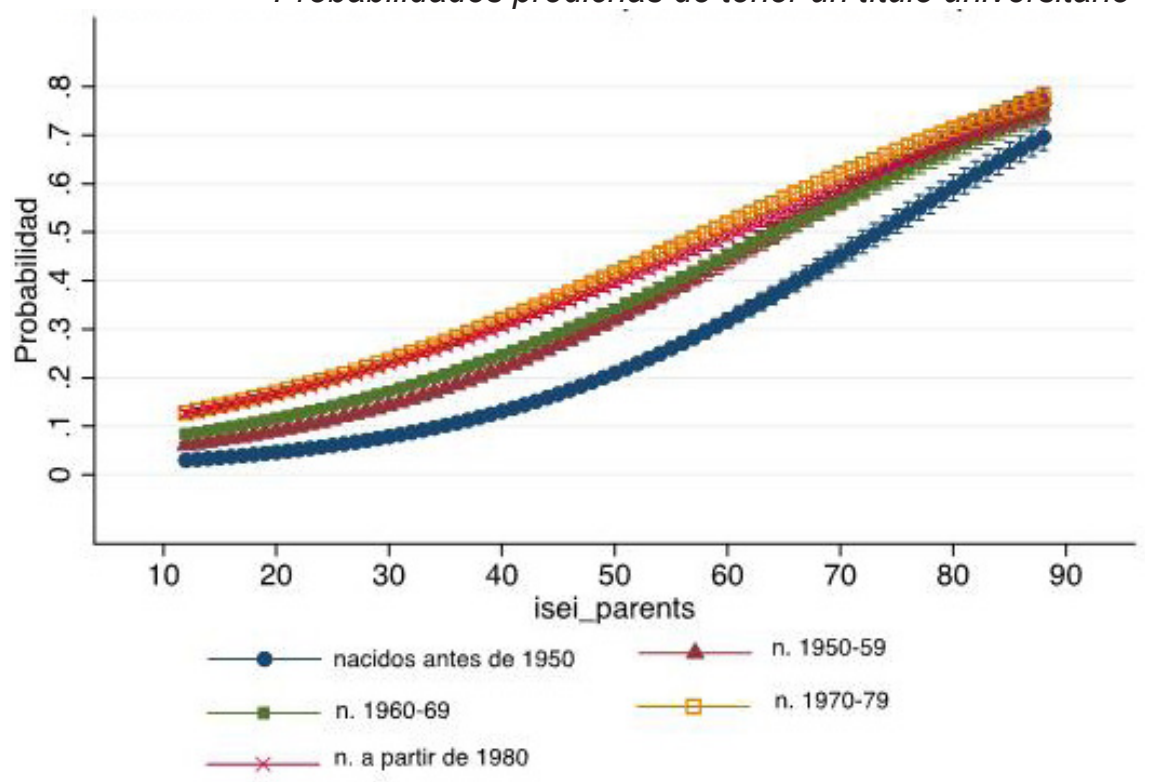

Algunas ocupaciones de la escala ISEI: 12= peones agrícolas; $16=$ trabajadores cualificados de la agricultura;

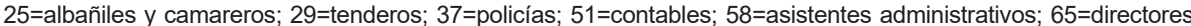
de empresas de servicios profesionales; 71=profesores de primaria; 79=ingenieros (excepto agrónomos, de montes y eléctricos); 82=profesores de secundaria; 85= jueces, magistrados, abogados y fiscales=85; 89=médicos.

\section{El efecto del origen social por grupos de edad y por sexo}

\section{Gráfico 5.}

Probabilidades predichas de estar en el paro en función del origen social por grupos de edad sin controlar por el nivel educativo. Modelo de probabilidad lineal
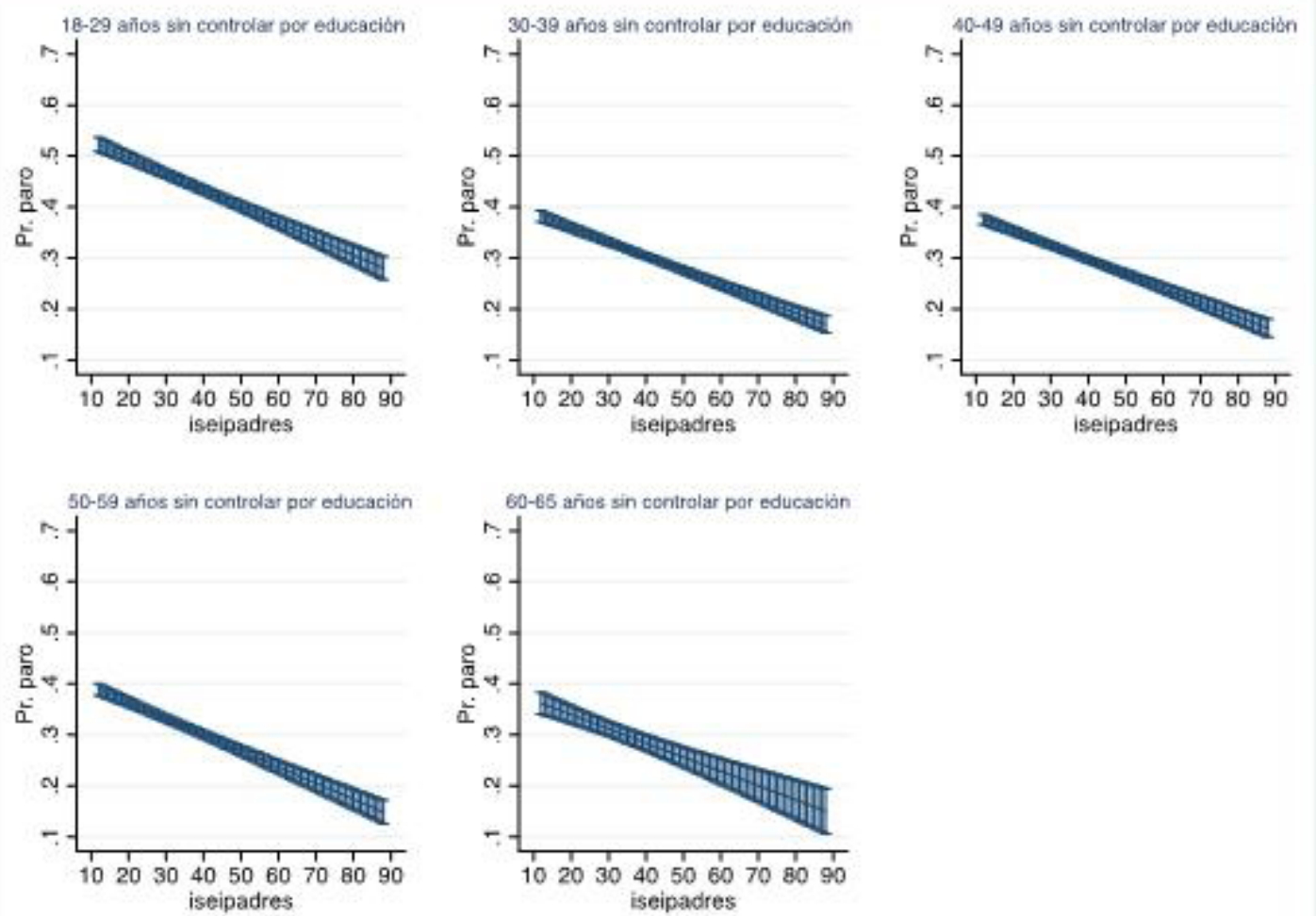

Variables independientes del modelo: año de la encuesta, sexo, ISEI de los padres, grupos de edad e interacción grupos de edad*ISEI de los padres. 


\section{Gráfico 6.}

Probabilidades predichas de estar en el paro en función del origen social por grupos de edad controlando por el nivel educativo. Modelo de probabilidad lineal
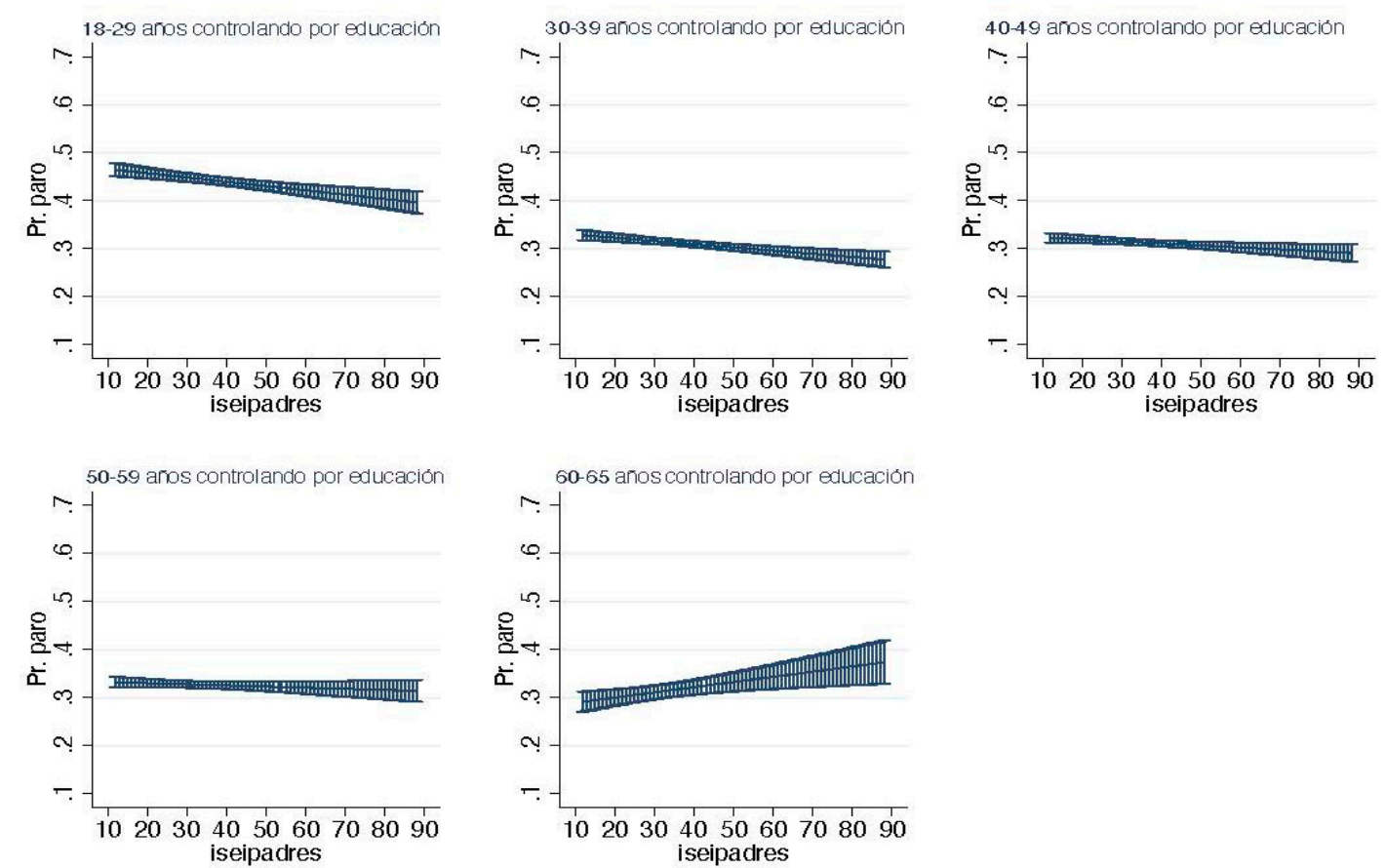

Variables independientes del modelo: año de la encuesta, sexo, nivel educativo, ISEI de los padres, grupos de edad e interacción grupos de edad*ISEI de los padres.

\section{Gráfico 7.}

Probabilidades predichas de estar en el paro en función del origen social para varones y mujeres. Modelo de probabilidad lineal
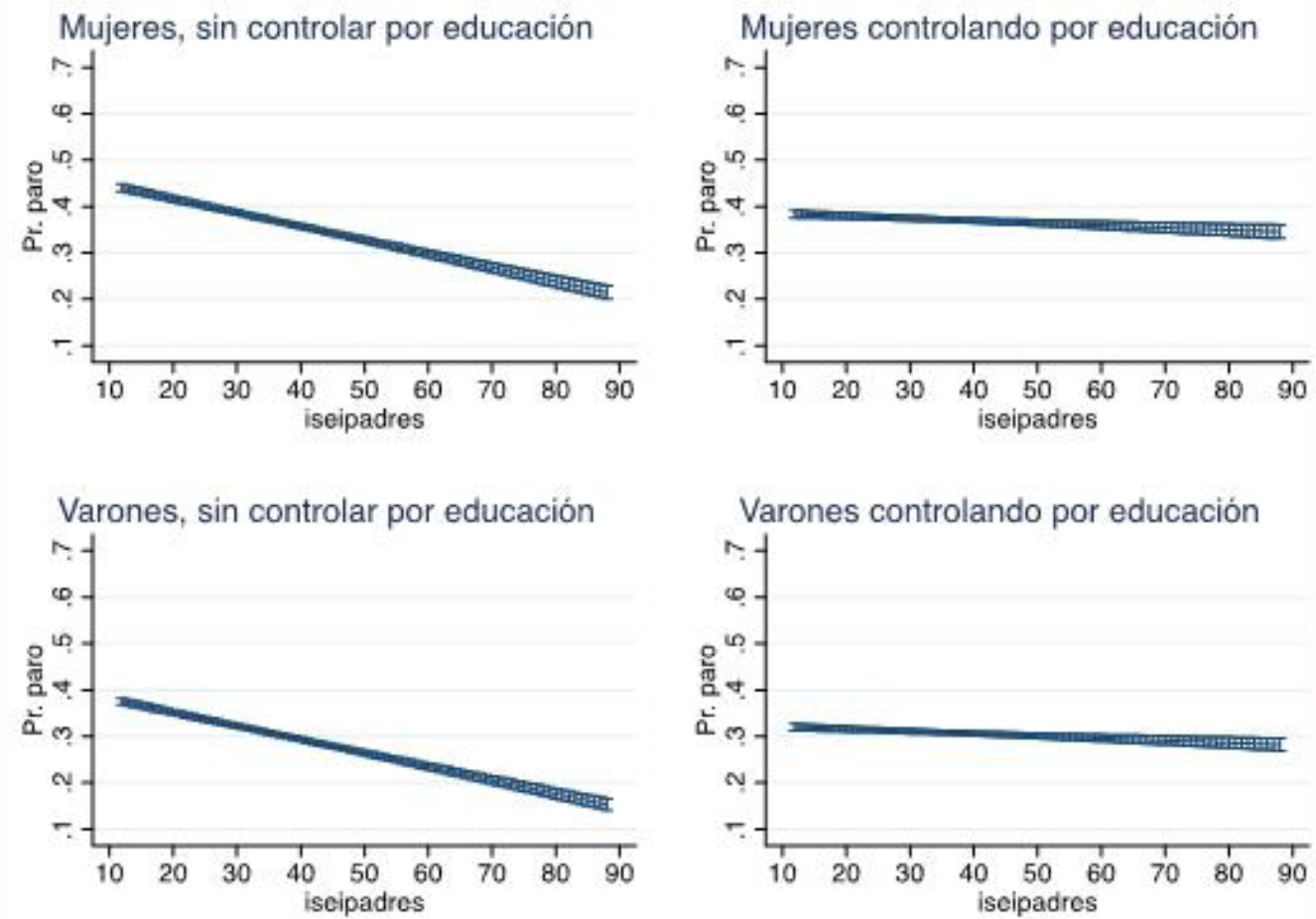

Variables independientes de los modelos: año de la encuesta, sexo, ISEI de los padres, grupos de edad (18-39 años y 40 años o más) e interacción ISEI de los padres por sexo. Los gráficos de la derecha también controlan por nivel educativo. 
JUAN IGNACIO MARTÍNEZ PASTOR es profesor titular de Sociología en el Departamento de Sociología II (Estructura Social) de la Universidad Nacional de Educación a Distancia (UNED). Ha publicado artículos sobre la sociología del trabajo, estatificación social y la sociología de la familia en revistas como la European Sociological Review, Demographic Research, Journal of Ethnic and Migration Studies, International Journal of Comparative Sociology, Revista Internacional de Sociología, Revista Española de Investigaciones Sociológicas o South European Society and Politics. Su último libro se titula Los datos sin tapujos. Cómo interpretar y difundir las estadísticas sociales. 